The Research Journal of the Costume Culture

[Original Article]
Received May 19, 2017 Revised June 22, 2017 Accepted July 03, 2017

${ }^{\dagger}$ Corresponding author (hjha@smu.ac.kr)

ORCID

Ok Jin Seong

http://orcid.org/0000-0003-4414-1860 HEE JUNG HA

http://orcid.org/0000-0002-3706-1363

This work was supported by the National Research Foundation of Korea Grant funded by the Korean Government(NRF-2014S1A5B5 A02015110).

\title{
Study on torso patterns for elderly obese women for vitalization of the silver clothing industry \\ - Applying the CLO 3D program -
}

\author{
Ok jin Seong and Hee Jung $\mathrm{Ha}^{{ }^{* \dagger}}$ \\ Lab. of Fashion Design, Sejong University, Korea \\ Dept. of Clothing and Textiles, Sangmyung University, Korea*

\section{실버 의류산업 활성화를 위한 노년 비만여성의 토르소 원형 연구 - CLO 3D 가상착의 시스템 활용 -}

\author{
성 옥 진·하 희 정 ${ }^{*+}$ \\ 세종대학교 패션디자인연구소, 상명대학교 의류학과*
}

\begin{abstract}
The purpose of this study was to suggest torso patterns that fit the three main body shapes of elderly obese women. To reduce time, costs, and also the trial and error needed to make patterns, the CLO program for 3D test wear was employed. Three virtual models for aged obese women were use, with the YUKA system used to produce torso patterns. 3D simulation of test wear and corrections was done to design optimal torso patterns. The results were as follows: First, for the three models of obese women's body shapes as realized by CLO 3D, Type 1 is lower-body obesity shapes, Type 2 is abdominal obesity shapes, and Type 3 is whole-body obesity shapes. Second, to design the study patterns, actual measurement values, back waist length and waist to hip length, were used. The armhole depth $(\mathrm{B} / 4-1.5)$, front interscye $(B / 6+2.3)$, front neck width $(B / 12-0.5)$, front neck depth $(B / 12+0.5)$, front waist measurement $(\mathrm{W} / 4+1.5+\mathrm{D})$, front hip measurement $(\mathrm{H} / 4+2+0.5)$, and back hip measurement $(\mathrm{H} / 4+3-0.5)$ were calculated using formulas. Third, according to the results of test-wearing the study patterns, reduced front neck width and depth improved the neck fit and reduced armhole depth bettered loose or plunging armhole girth and also reduced the sagging of bust c.. Also, tight sidesfrom aprotruded waist and abdomen improved with the increase of surpluses in the back waist and also back and front hip c. The exterior was enhanced by displacement of back and front darts, which distributed surpluses better.
\end{abstract}

Keywords: elderly obese women(노년 비만여성), silver clothing industry(실버의류산업), obesity body type(비만체형), torso pattern(토르소 원형), CLO 3D(가상착 의 프로그램) 


\section{Introduction}

평균수명의 연장으로 노인 인구가 많아지는 고령 화는 세계적인 추세이고, 우리나라의 60 70대 노년층 도 은퇴 후 넉넉한 노후자금을 바탕으로 여유로운 생 활을 즐기고, 자신의 건강과 품위를 유지하는데 소비 를 아끼지 않는 집단이다. 이러한 노년층에 대한 관 심은 실버산업으로 범위를 넓혀 여러 분야의 산업에 서 활기를 띠고 있는데, 노년층은 과거에 비해 경제 적 능력과 사회활동의 기회 증가로 라이프스타일이 변화되고, 여가시간의 활용으로 활동범위가 넓어지면 서 의복에 대한 관심도가 높아졌으며, 자신들에게 잘 맞는 의복이 생산되기를 원하고, 맞음새 또한 중요한 부분으로 대두되고 있다(Lee \& Suh, 2010).

그러나 노년으로 갈수록 체형의 변화를 겪게 되고, 특히 노년 비만여성은 연령이 증가할수록 키가 작아 지며, 허리둘레, 배꼽수준허리둘레는 크게 증가하고, 복부비만도가 큰 것으로 나타났으며, 다리와 같은 하 체부분은 가늘어지는 것으로 나타났다. 따라서 패턴 설계 시 증가하는 배둘레와 엉덩이둘레의 비례, 배둘 레와 가늘어지는 허벅지둘레의 비례를 고려한 설계 가 필요(Seong \& Kim, 2015)하지만, 비만여성은 외 모에 대한 자심감이 부족하여 타인 앞에 나서기를 주 저하며, 심리적인 위축감이 커서 비만체형의 피험자 를 대상으로 한 체형분석이나 패턴개발이 어려운 실 정이다(Lim, 2010).

최근에는 디지털 패션의 생산기술 향상으로 $3 \mathrm{D}$ 프 로그램을 활용한 패턴개발이 이루어지고 있는데, 가 상의 인체모형에 착의하므로 다양한 치수와 체형을 커버하는 것이 가능하고, 여러 단계의 패턴 수정과정 을 줄일 수 있어 생산 초기 단계에 샘플 제작 비용을 비롯해 시간과 노력을 줄일 수 있고, 다양한 패턴을 그래픽 작업을 통해 가상의 공간에서 시뮬레이션(피 팅)을 할 수 있어, 착용시 생기는 문제점을 사전에 알 수 있다는 장점이 있다(Kim, Choi, Jo, Yang, \& Na, 2015). 또한 의복디자인 변경에 따른 패턴변경이 용 이하고, 3D 시뮬레이션을 통한 가상 피팅은 의복압과 투명도 등을 조절하여 완성된 의복의 맞음새와 착장 상태를 확인할 수 있으므로, 직관적인 의복디자인과 패턴수정이 무한히 가능하여 의류제품 개발과 생산 에 따른 시행착오, 시간, 비용 등을 절감하여 기업의 이윤을 극대화시킬 뿐 아니라, 합리적인 생산시스템
구축이 가능하게 될 것이다(Lee \& Sohn, 2011).

이와 같이 디지털 패션의 생산기술이 활성화되면 서 $3 \mathrm{D}$ 가상착의 시스템을 활용한 연구도 활발히 진 행되고 있다. 그 중 의복구성 측면에서 $3 \mathrm{D}$ 가상착의 프로그램을 이용한 패턴개발의 타당성 검증은 중요한 부분으로 많은 연구가 진행되어 왔다. 실제로 가상착 의 적합성을 검증한 연구에서 가상착의와 실제착의 를 다양한 소프트웨어(Clo $3 \mathrm{D}$ (클로버추얼패션), $\mathrm{DC}$ Suite(서울대학교), I-Fashion(건국대학교))를 활용하 여 비교 연구하였는데, 실제착의와 가상착의 평가 결 과가 유사한 것으로 나타났다.

Choi and Do(2008)와 Do and Park(2010)은 Idesigner라는 소프트웨어를 사용하여 실제 착의와 가 상착의를 비교하였고, Kim, Yin, and Song(2014)은 3 가지 프로그램(Clo 3D, i-Designer, 3D Runway Designer)를 사용하여 착의 상태를 검증하였는데, 각 프 로그램의 고유의 시뮬레이션 기능차이가 있을 뿐 실제 착의와 가상착의 외관평가는 유사한 것으로 나타났다. Hong (2013)과 Lee and Sohn(2012)과 Yoon(2013)은 CLO 3D 프로그램을 사용하여 가상 착의와 실제 착 의가 유사함을 증명하였다. 최근에는 이러한 검증된 연구를 바탕으로 패턴을 비교 분석하는 연구에서 가 상착의 실험을 통해서 패턴을 제시하는 연구 (Hong, Kim, \& Uh, 2015; Kim, Hong, \& Uh, 2014; Kim, Kim, \& Park, 2014; Li, 2013; Lim, 2010; Lim, 2013) 가 많아지는 추세이다.

따라서 본 연구는 이미 많은 검증과정을 거쳐 확인 된 $3 \mathrm{D}$ 가상착의 프로그램을 활용하여 가상모델을 제 작하고, YUKA 시스템을 이용하여 토르소 원형을 제 작한 후, 3D 시뮬레이션을 통해 가상착의 및 보정을 하여 노년비만 여성의 체형에 적합한 토르소 원형을 제시하는데 연구목적이 있다. 이러한 노년 비만여성의 신체에 대한 정보와 패턴연구는 의복착용의 만족도 를 높일 뿐 아니라, 의복의 생산을 위한 기초자료로 활용되어 생산효율성을 극대화시킬 수 있을 것이다.

\section{Methods}

\section{Selection of subjects and production of 3D avatar}

본 연구는 선행연구(Seong \& Kim, 2015)를 참고 로 하여 '제5차 한국인 인체치수조사' 자료(Korean 
Agency for Technology and Standards, 2004) 중 60 79세의 노년 여성을 대상으로 Rohrer 지수 1.6 이상, 체질량지수(BMI) 25 이상, 복부지방율(WHR) 0.85 이상을 만족시키는 비만여성을 연구집단으로 선정하 였다. 또한 5 차 한국인 인체치수조사 자료를 선택한 이유는 5차 조사의 경우, 60 90세까지를 피험자로 선 택한 반면, 6차 한국인 인체치수조사 자료는 60 69세 까지를 피험자로 선정하고 있어 연령 및 피험자수를 확대하여 연구하고자 5차의 인체자료를 선택하였다. 선정된 피험자는 측정항목 중 결항이 있는 피험자를 제외한 658 명의 자료를 사용하였다. 〈Table 1〉은 비 만 판정기준 및 연구대상의 인원수를 분석한 것으로 세 가지 비만지수(BMI, Rohrer, WHR)를 모두 만족 시키는 인원 340 명을 연구대상으로 하였다. 〈Table 2)는 선행연구(Seong \& Kim, 2015)에서 분류된 3가 지 비만유형의 형태를 CLO 3D 프로그램을 통해 구 현하여 제시한 것이고, 〈Table 3〉은 인체 모형 구현에 사용된 비만유형의 신체사이즈이다. 분류된 비만유형 중 유형 1 은 상체에 비해 배가 발달한 하체비만 체형 이고, 유형 2 는 허리가 비만해서 가슴부터 배까지 일 자형태를 이루는 비만형으로 상체가 발달한 복부비 만 체형이다. 유형3은 전체가 비만하지만 균형 잡힌 비만형으로 전신비만 체형이다.

\section{Design of torso pattern}

CLO 3D 프로그램에 의해 구현된 3개 체형의 노년 비만여성 아바타를 사용하여 착의실험을 하였고, 연 구원형 설계를 위해 비교원형을 선정하였다. 비교원 형 선정을 위해 대학교재용으로 사용되고 있는 원형
$<$ Table 2> Body types of elderly obese women

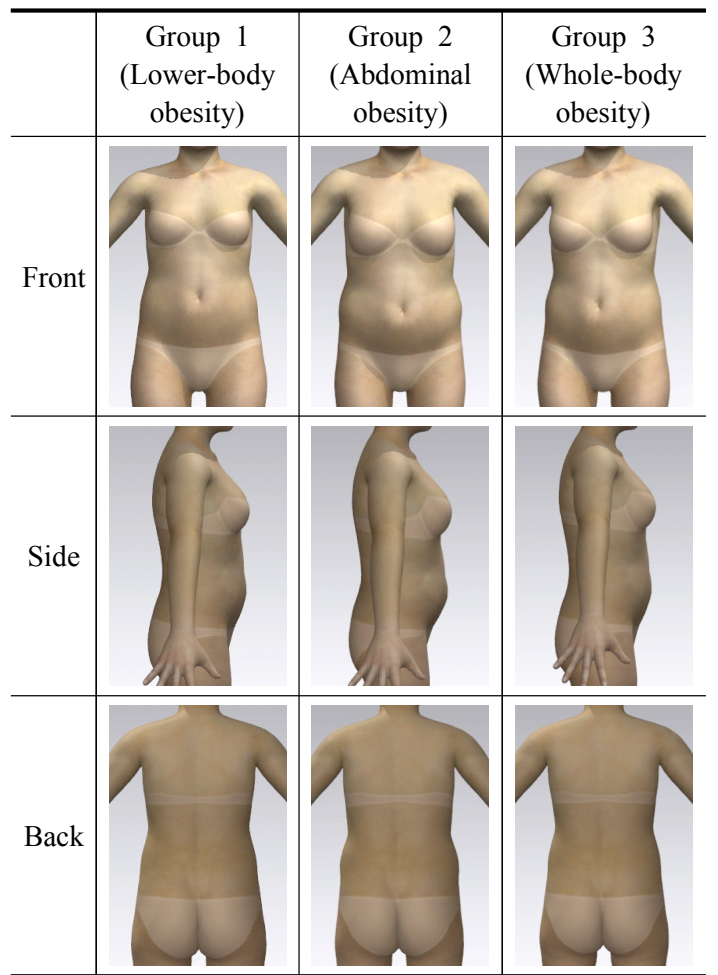

(Lee, Yoon, Park, \& Nam 2013; Ryu, 2001)을 제도 하여 착의시킨 결과, 가슴과 배둘레의 비만으로 인해 특히 햄라인 들림현상과 배둘레 당김현상이 나타나, 이를 보완할 수 있도록 앞처짐 분량이 좀 더 크고, 뒤 중심선에서 허리와 엉덩이로 들어오는 분량이 적어 당김현상을 완화할 수 있는 유희숙의 여성용 토르소 원형(Ryu, 2001)을 비교원형으로 사용하였다. 비교원

$<$ Table 1> The obesity diagnosis criteria and number of subjects

\begin{tabular}{|c|c|c|c|c|c|c|}
\hline \multirow{2}{*}{ Index } & \multirow{2}{*}{\multicolumn{2}{|c|}{ Diagnose criteria }} & \multirow{3}{*}{$\begin{array}{c}\begin{array}{c}\text { Number } \\
(\%)\end{array} \\
300(88.2)\end{array}$} & \multicolumn{3}{|c|}{ Obesity rate } \\
\hline & & & & 60 age $(n=195)$ & 70 age $(n=145)$ & $\operatorname{Total}(n=340)$ \\
\hline \multirow{2}{*}{ BMI } & Obese class 1 & $25 \sim 29.9$ & & \multirow{2}{*}{27.53} & \multirow{2}{*}{27.50} & \multirow{2}{*}{27.52} \\
\hline & Obese class 2 & $\geq 30.0$ & $40(11.8)$ & & & \\
\hline Rohrer & Obesity & $\geq 1.6$ & $340(100)$ & 1.82 & 1.84 & 1.83 \\
\hline WHR & Obesity & $\geq 0.85$ & $340(100)$ & 0.95 & 0.98 & 0.97 \\
\hline
\end{tabular}

Rohrer $=$ Weight / stature $(\mathrm{cm})^{3} \times 10^{5}$

$\mathrm{BMI}=$ Weight $/$ stature $(\mathrm{m})^{2}$

WHR=Waist rcumference - Hip circumference 
(Unit: cm)

\begin{tabular}{|c|c|c|c|c|}
\hline \multicolumn{2}{|r|}{ Item } & Lower-body obesity & Abdominal obesity & Whole-body obesity \\
\hline \multirow{2}{*}{ Height } & Waist height & 92.32 & 92.24 & 92.21 \\
\hline & Hip height & 72.83 & 73.90 & 72.57 \\
\hline \multirow{9}{*}{$\begin{array}{l}\text { Circum } \\
\text { ference }\end{array}$} & Bust circumference & 95.54 & 100.58 & 97.15 \\
\hline & Waist circumference & 88.28 & 95.62 & 89.78 \\
\hline & Waist C.(omphalion) & 97.54 & 99.06 & 94.86 \\
\hline & Hip circumference & 95.45 & 94.77 & 94.52 \\
\hline & Thigh circumference & 54.06 & 53.02 & 54.10 \\
\hline & Knee circumference & 35.82 & 35.37 & 35.39 \\
\hline & Calf circumference & 33.42 & 33.30 & 34.43 \\
\hline & Upper arm circumference & 29.56 & 29.81 & 30.52 \\
\hline & Wrist circumference & 16.09 & 16.13 & 16.45 \\
\hline \multirow{5}{*}{ Length } & Interscye, front & 32.95 & 33.33 & 33.59 \\
\hline & Back interscye, length & 36.02 & 37.03 & 36.81 \\
\hline & Waist back length & 37.97 & 40.32 & 39.23 \\
\hline & Biacromion length & 38.76 & 38.86 & 39.06 \\
\hline & Arm length & 52.45 & 53.32 & 52.60 \\
\hline
\end{tabular}

형은 아바타에 착의된 상태에서 패턴을 바로 수정하 는 방식으로 설계하였다. 이러한 방식은 선행연구 $(\mathrm{Lim}$, 2013)를 참고로 한 것으로 YUKA 프로그램을 통해 패턴을 제작하고 .dxf 파일로 저장한 후 CLO 3D 프 로그램에서 .dxf 파일을 불러와 시뮬레이션을 시행하 는 방법이다. 이러한 방법은 착장 상태에서 바로 패 턴창을 띄워 수정이 가능하여 착의상태를 확인할 수 있는 장점이 있어 YUKA 프로그램에서 패턴을 다시 불러오는 번거로움이 없이 작업할 수 있다. 따라서 본 연구는 이러한 특성을 바탕으로 3 가지 체형에 모 두 적합한 토르소 원형 개발을 위해 패턴창에서 여러 번의 수정 단계를 거처 시뮬레이션하여 패턴을 완성 하여 제시하였다.

\section{Evaluations of virtual garment simulation}

토르소 원형의 가상착의 평가를 위해 사용된 프로 그램은 (주)클로 버츄얼 패션의 CLO 3D Marvelous Designer v.4.30의 최신 버전으로 시뮬레이션을 실시
하였다. 가상착의 평가는 착장 시뮬레이션 및 투시도 와 변형률, 접촉면을 비교하여 분석하였다.

1) Fabrics for CLO 3D

2) 토르소 원형에 사용된 소재는 CLO 3D 프로그램 에 내장되어 있는 Real_Cotton_Cloth_VI를 적 용하였다.

3) Opacity는 여유분 비교를 쉽게 할 수 있는 기능으 로 $0 \sim 100 \%$ 의 범위 중 $40 \%$ 로 설정하여 아바타 와 의상 사이의 간격을 시각적으로 비교하였다.

4) Strain은 아바타에 의상을 착장시켰을 때, 아바 타와 의상의 밀착 정도를 알아보기 위한 것으로 의상이 아바타에게 잘 맞는지, 너무 타이트한지 를 확인할 수 있다. 변형률의 분포는 100 120\% 까지로 닿아있는 곳의 색이 연두, 노랑, 주황, 빨 강으로 변화되는데, $100 \%$ 에 가까우면 연두색, $120 \%$ 에 가까우면 적색을 나타내어 녹색에 가 까우면 여유분이 많다는 의미이고, 적색에 가까 우면 여유분이 없다는 것을 의미한다. 
5) Show pressure point는 아바타와 의상이 닿는 곳에 청색점이 분포하는데, 분포가 많을수록 여 유가 적고, 압력을 받는 위치임을 알 수 있다.

6) Appearance evaluation는 선행연구(Lim, 2013; Kim, 2007; Yoon, 2013)를 참조하여 정면, 측면, 후면 에 대한 사진을 보고, 각 부위의 여유량, 기준선의 위치, 실루엣 등을 관찰하여 5점 척도로 평가 하였다. 총 평가항목은 27 문항이고, 평가자는 의 류학을 전공한 전문가집단 10 인을 선정하였다.

\section{Data analysis}

본 연구의 자료는 SPSS 21.0 통계프로그램을 이용 하여 분석하였으며, 패턴 간의 차이를 분석하기 위해 분산분석(ANOVA)과 Duncan Test를 사용하였다.

\section{Results and Discussion}

\section{Evaluations of virtual garment simulation for} comparative patterns by group

노년 비만여성의 체형에 적합한 토르소 원형을 개
발하고자 각 체형별 비교원형의 가상착의 상태를 살 펴본 결과를 〈Table 4〉에 제시하였고, 외관평가 결과 를〈Table 5〉에 제시하였다. 유형 1은 앞목둘레가 크 고 앞배부위의 들뜸현상과 뒤허리둘레의 여유가 많 아 보이나, 뒤엉덩이둘레에 여유가 적어 보이는 것을 빼면, 다른 체형에 비해 비교적 안정된 형태를 유지 함을 알 수 있고, 유형 2는 목둘레가 넓고 암홀이 크 며 복부 비만으로 인해 배 부위가 당기고 뒤허리둘레 는 여유가 많고 뒤엉덩이둘레는 여유가 적어 변형률 이 노란색을 띄고 있다. 또한 뒤다아트가 중심 쪽으 로 몰려있어 여유량이 한쪽으로 몰려 있다. 유형 3도 유형 2와 유사한 상태를 나타내고 있음을 알 수 있는 데 외관평가 결과를 살펴보면, 목둘레선의 형태는 모 든 체형에서 큰 것으로 나타나 젖가슴둘레를 기준으 로 치수를 설정하다보니 목둘레선이 넓고 깊게 파여 좋지못한 외관을 형성한 것으로 보인다. 암홀의 상태 는 가슴이 비교적 작은 유형 1 을 빼고 나머지 두 체 형 모두 넓고 깊게 파여 겨드랑 부위가 들뜨고 젖가 슴둘레선이 아래로 처지는 현상이 발생하였는데, 이 는 젖가슴둘레를 기준으로 한 계산식의 영향이라 여

$<$ Table 4> 3D appearance of comparative patterns

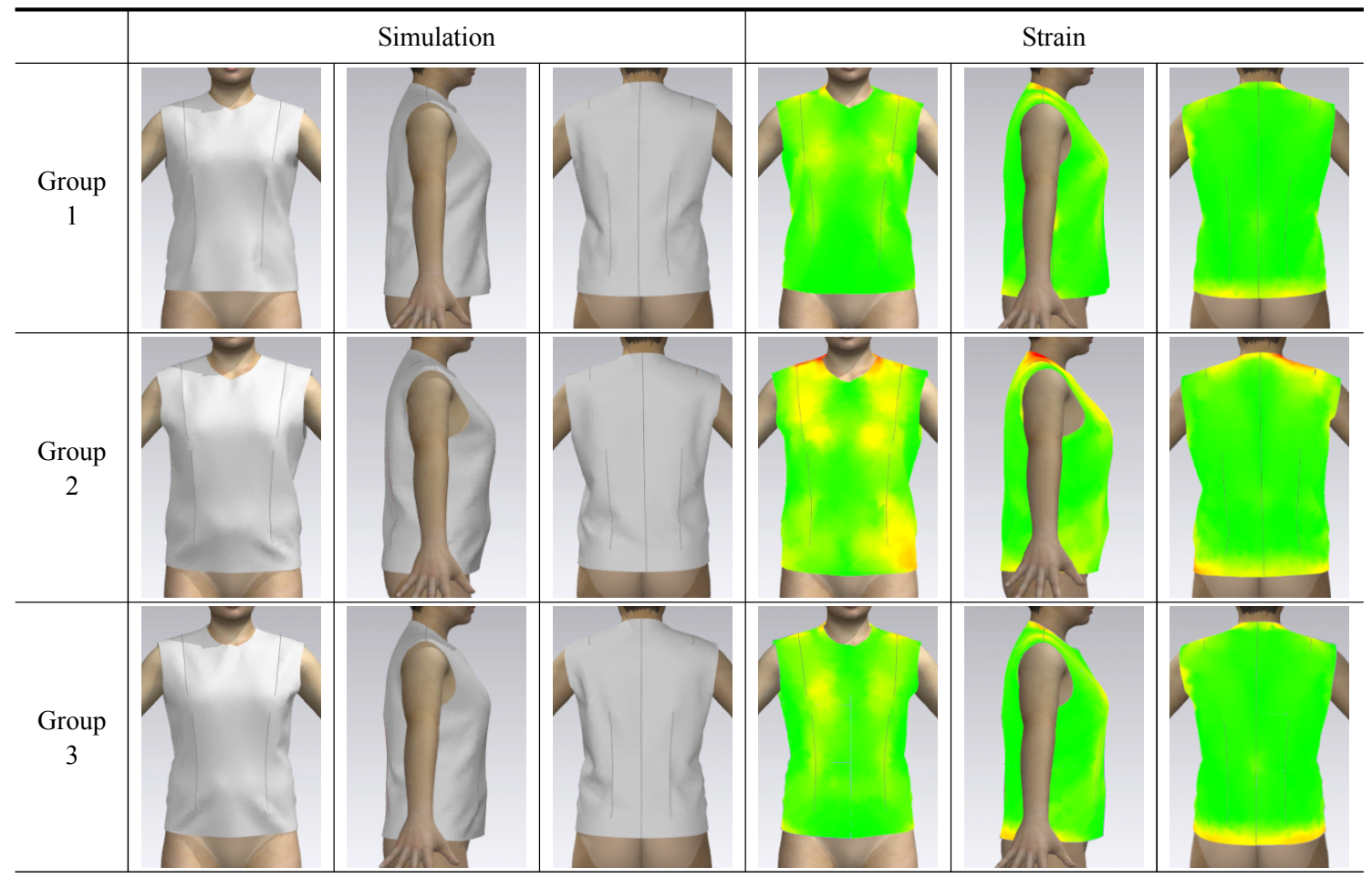


$<$ Table 5> Appearance evaluation of comparative patterns by group

\begin{tabular}{|c|c|c|c|c|c|c|c|}
\hline \multirow{2}{*}{ Item } & \multicolumn{2}{|c|}{ Group 1} & \multicolumn{2}{|c|}{ Group 2} & \multicolumn{2}{|c|}{ Group 3} & \multirow{2}{*}{$F$-value } \\
\hline & Mean & S.D & Mean & S.D & Mean & S.D & \\
\hline Natural neck line & 2.63 & 0.52 & 2.25 & 0.46 & 2.38 & 0.50 & 1.17 \\
\hline Armhole & $2.88 \mathrm{~A}$ & 0.64 & $2.00 \mathrm{~B}$ & 0.53 & $2.38 \mathrm{AB}$ & 0.65 & $4.80^{*}$ \\
\hline Front \& back interscye & 2.75 & 0.46 & 2.25 & 0.46 & 2.38 & 0.51 & 2.33 \\
\hline Ease of bust area & 2.13 & 0.64 & 1.75 & 0.46 & 2.25 & 0.55 & 1.94 \\
\hline Ease of waist area & 2.75 & 0.46 & 2.13 & 0.64 & 2.50 & 0.59 & 2.61 \\
\hline Ease of abdomen area & $2.75 \mathrm{~A}$ & 0.46 & $1.75 \mathrm{~B}$ & 0.71 & $2.13 \mathrm{~B}$ & 0.66 & $7.30^{* * *}$ \\
\hline Ease of hip area & $2.88 \mathrm{~A}$ & 0.35 & $2.25 \mathrm{~B}$ & 0.46 & $1.63 \mathrm{C}$ & 0.68 & $15.44^{* * *}$ \\
\hline Position of waist dart & 2.38 & 0.52 & 1.88 & 0.64 & 1.88 & 0.62 & 1.84 \\
\hline Overall appearance & $2.63 \mathrm{~A}$ & 0.52 & $1.75 \mathrm{~B}$ & 0.71 & $2.00 \mathrm{~B}$ & 0.68 & $4.63^{*}$ \\
\hline
\end{tabular}

${ }^{*} p<.05,{ }^{* *} p<.01,{ }^{* * *} p<.001, \mathrm{~A}>\mathrm{B}>\mathrm{C}$

겨지며, 40 60대 비만여성을 연구한 $\operatorname{Kim}(2007)$ 의 연 구결과와 같다. 허리둘레의 경우, 모든 체형에서 뒤허 리둘레의 여유가 많아, 좋지 못한 외관을 보여주고 있으며, 배 부위 당김현상은 유형 2와 유형 3에서 두 드러지게 나타났고 엉덩이 부위의 당김현상도 유형 2 와 유형3에서 두드러지게 나타나 유형 1과 차이를 나 타내었다. 따라서 이를 바탕으로 목둘레 여유량, 진동 깊이와 젖가슴둘레선의 위치, 뒤허리둘레와 앞뒤엉덩 이둘레의 여유량에 대한 보정이 필요한 것으로 나타 났고, 여유량 배분에 따른 앞뒤 다이트 위치의 적절 성도 고려하여 최종 연구원형을 설계하였다.

\section{Design of developed patterns}

비교원형의 가상착의 평가 결과를 바탕으로 비교 원형을 수정하였는데, 먼저 비교원형은 진동둘레의 들 뜸과 진동깊이의 깊게 파임, 젖가슴둘레선의 처짐으 로 인해 외관이 좋지 못한 것으로 나타나, 연구원형 은 젖가슴둘레를 가로 $(\mathrm{B} / 2+4)$ 로 $1 \mathrm{~cm}$ 줄여주고, 등길 이는 비교원형과 동일하게 실측치를 이용하였다. 진 동깊이는 $1.5 \mathrm{~cm}$ 를 줄여 젖가슴둘레선을 올려주었다. 비만할수록 앞뒤품보다 두께가 커지는 경향을 보이므 로 겨드랑앞벽사이길이(앞품)을 $0.7 \mathrm{~cm}$ 줄여주어 겨드 랑앞벽사이길이(앞품), 겨드랑뒤벽사이길이(뒤품), 겨 드랑부위의 간격을 조정하였다. 목둘레 부위의 들뜸 현상을 수정하기 위해 뒷목너비는 비교원형과 동일
하게 사용하고, 앞목너비는 $0.5 \mathrm{~cm}$ 줄여주고 앞목깊이 는 $1 \mathrm{~cm}$ 줄여주었다. 앞허리와 배의 돌출로 뒤허리쪽 으로 당겨지는 현상을 개선하기 위해 앞허리둘레는 그 대로 두고, 뒤허리둘레를 $0.5 \mathrm{~cm}$ 키워주고 앞엉덩이둘 레는 $1 \mathrm{~cm}$, 뒤엉덩이둘레는 $2 \mathrm{~cm}$ 키워 배와 엉덩이둘 레의 여유량을 보충하였다.

이것으로 전체적인 외관은 좋아졌으나, 유형 1 의 경우 앞 들림 현상이 있어 이를 좀더 개선하기 위해 앞 처짐을 $0.5 \mathrm{~cm}$ 늘려주고, 뒤중심선에서 허리와 엉덩이 선으로 들어오는 분량을 $0.5 \mathrm{~cm}$ 로 줄여주고, 옆허리선 을 설정하는 들임분량을 $0.5 \mathrm{~cm}$ 줄여 허리와 엉덩이 둘레의 여유량을 좀 더 늘려주었다. 또한 젖꼭지사이 수평길이(유폭)을 $1 \mathrm{~cm}$ 늘려주고 앞뒤다아트의 위치 를 조정하고 여유량을 분산하였으며, 뒤허리다아트를 뒤허리선 가운데로 위치를 조정하여 여유량을 분산 시켜 외관을 향상시켰다.

\section{Evaluations of virtual garment simulation for} developed patterns by group

비교원형의 수정결과로 완성된 연구원형의 가상착 의 결과와 외관평가 결과를 〈Table 6〉과 〈Table 7〉에 제시하였다.

이를 살펴보면〈Table 6〉의 연구원형은 앞목너비 와 앞목깊이의 축소로 목둘레의 들뜸현상이 개선되 었고 측면에서 보면 진동깊이의 축소로 진동둘레의 
$<$ Table 6> 3D Appearance of developed patterns

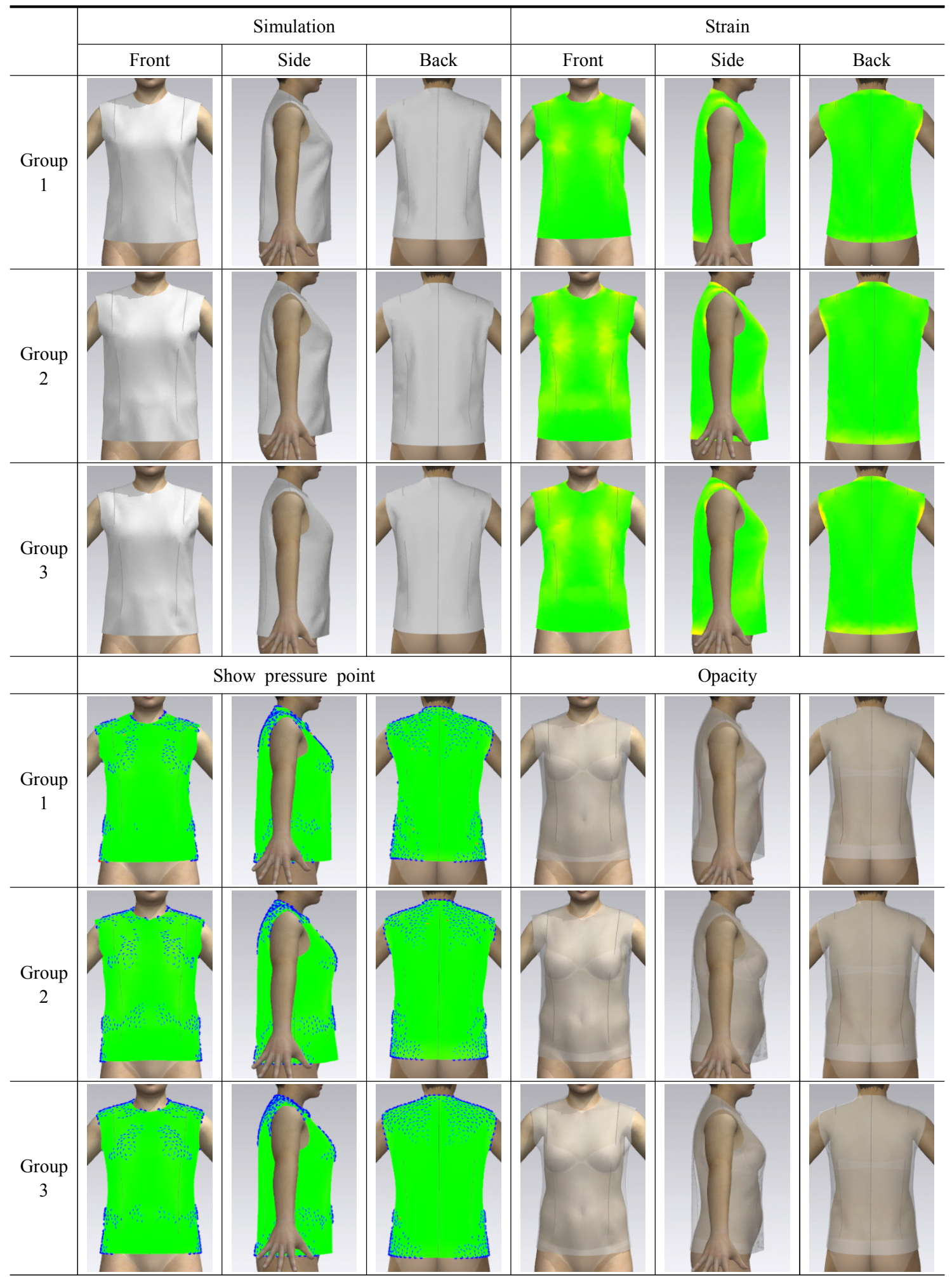


들뜸이나 파임이 개선되고, 젖가슴둘레의 처짐이 완 화되었다. 또, 허리와 배 돌출로 인한 측면의 당김현 상은 뒤허리둘레와 앞뒤엉덩이둘레의 여유량 증가와 뒤허리선과 옆허리선의 들임분량 축소로 인한 허리 여유량의 증가로 개선되었고, 앞뒤다아트의 위치이동
으로 인해 여유량이 적당이 배분되어 외관이 향상되 었음을 알 수 있다. 외관평가 결과는 〈Table 7〉에서 보듯이 세 체형 모두에서 비교적 고르게 평가되어 비 교원형에 비해 연구원형이 노년 비만체형에 적합한 원형임을 알 수 있다.

<Table 7> Appearance evaluation of developed patterns by group

\begin{tabular}{|c|c|c|c|c|c|c|c|c|}
\hline & \multirow{2}{*}{ Item } & \multicolumn{2}{|c|}{ Group 1} & \multicolumn{2}{|c|}{ Group 2} & \multicolumn{2}{|c|}{ Group 3} & \multirow{2}{*}{$F$-value } \\
\hline & & Mean & S.D & Mean & $S . D$ & Mean & S.D & \\
\hline \multirow{10}{*}{ Front } & Natural neck line & 4.38 & 0.52 & 4.38 & 0.52 & 4.38 & 0.52 & 0.00 \\
\hline & Neck depth & 4.38 & 0.52 & 4.13 & 0.64 & 4.50 & 0.53 & 0.91 \\
\hline & Biacromion length & 4.13 & 0.83 & 4.13 & 0.64 & 4.50 & 0.53 & 0.81 \\
\hline & Ease of front interscye & 4.13 & 0.64 & 4.13 & 0.64 & 4.38 & 0.52 & 0.46 \\
\hline & Ease of armhole & 3.88 & 0.64 & 4.25 & 0.46 & 4.25 & 0.46 & 1.34 \\
\hline & Ease of bust area & 4.00 & 0.53 & 4.13 & 0.64 & 4.25 & 0.46 & 0.41 \\
\hline & Ease of waist area & 4.13 & 0.64 & 4.38 & 0.52 & 4.25 & 0.46 & 0.42 \\
\hline & Ease of abdomen area & 4.38 & 0.52 & 4.13 & 0.35 & 4.13 & 0.35 & 0.97 \\
\hline & Ease of hip area & $4.38 \mathrm{~A}$ & 0.52 & $3.75 \mathrm{~B}$ & 0.52 & $4.25 \mathrm{AB}$ & 0.46 & $3.77^{*}$ \\
\hline & Position of waist dart & 4.38 & 0.52 & 4.50 & 0.53 & 4.25 & 0.46 & 0.49 \\
\hline \multirow{4}{*}{ Side } & Armhole depth & 3.75 & 0.46 & 4.25 & 0.46 & 4.13 & 0.64 & 1.94 \\
\hline & Front armhole width & 3.88 & 0.64 & 4.25 & 0.46 & 4.25 & 0.46 & 1.34 \\
\hline & Back armhole width & 4.38 & 0.52 & 4.13 & 0.35 & 4.25 & 0.46 & 0.62 \\
\hline & Position of side line & 4.38 & 0.52 & 4.38 & 0.52 & 4.25 & 0.46 & 0.17 \\
\hline \multirow{8}{*}{ Back } & Neck breadth & 4.00 & 0.53 & 4.38 & 0.52 & 4.25 & 0.46 & 1.14 \\
\hline & Ease of back interscye & 4.00 & 0.53 & 4.25 & 0.46 & 4.25 & 0.46 & 0.70 \\
\hline & Ease of armhole & 4.38 & 0.52 & 4.00 & 1.31 & 4.50 & 0.53 & 0.72 \\
\hline & Ease of bust area & 4.13 & 0.35 & 4.25 & 0.46 & 4.50 & 0.53 & 1.40 \\
\hline & Ease of waist area & 4.38 & 0.52 & 4.25 & 0.46 & 4.25 & 0.46 & 0.18 \\
\hline & Ease of abdomen area & 4.00 & 0.53 & 4.25 & 0.46 & 4.63 & 0.52 & 3.09 \\
\hline & Ease of hip area & 4.13 & 0.35 & 3.75 & 0.46 & 3.88 & 0.35 & 1.89 \\
\hline & Position of waist dart & 4.38 & 0.52 & 4.25 & 0.46 & 4.38 & 0.52 & 0.17 \\
\hline \multirow{3}{*}{$\begin{array}{c}\text { Sil- } \\
\text { houette }\end{array}$} & Appearance of front & 4.25 & 0.46 & 4.50 & 0.53 & 4.25 & 0.46 & 0.70 \\
\hline & Appearance of back & 4.13 & 0.35 & 4.38 & 0.52 & 4.50 & 0.53 & 1.29 \\
\hline & Overall appearance & 4.63 & 0.52 & 4.38 & 0.52 & 4.50 & 0.53 & 0.46 \\
\hline
\end{tabular}

${ }^{*} p<.05,{ }^{* *} p<.01,{ }^{* * *} p<.001 \quad \mathrm{~A}>\mathrm{B}>\mathrm{C}$ 


\section{Suggestion of torso pattern for elderly obese} women

이상의 연구결과를 바탕으로 노년 비만여성의 체 형에 적합하고 신체적 만족도를 높일 수 있는 최적의 토스소 원형을 제시하고자 한다. 〈Table 8〉은 설계에 필요한 연구원형과 비교원형의 계산식을 비교하여 제시한 것이고, 〈Fig. 1〉은 토르소 원형의 제도법을 제

$<$ Table 8> Comparisons of formulas for pattern making

(Unit: $\mathrm{cm}$ )

\begin{tabular}{|c|c|c|}
\hline Items & $\begin{array}{c}\text { Comparative } \\
\text { pattern }\end{array}$ & $\begin{array}{l}\text { Developed } \\
\text { pattern }\end{array}$ \\
\hline Bust circumference & $\mathrm{B} / 2+5$ & $\mathrm{~B} / 2+4$ \\
\hline Waist back length & $\begin{array}{l}\text { Measured } \\
\text { value }\end{array}$ & $\begin{array}{l}\text { Measured } \\
\text { value }\end{array}$ \\
\hline Armhole depth & $\mathrm{B} / 4$ & $\mathrm{~B} / 4-1.5$ \\
\hline Front interscye & $\mathrm{B} / 6+3$ & $\mathrm{~B} / 6+2.3$ \\
\hline Back interscye & $\mathrm{B} / 6+4.5$ & $\mathrm{~B} / 6+4.5$ \\
\hline Back neck width & $\mathrm{B} / 12$ & $\mathrm{~B} / 12$ \\
\hline Front neck width & $\mathrm{B} / 12$ & $\mathrm{~B} / 12-0.5$ \\
\hline Front neck depth & $\mathrm{B} / 12+1.5$ & $\mathrm{~B} / 12+0.5$ \\
\hline Front waist measurement & $\mathrm{W} / 4+1.5+\mathrm{D}$ & $\mathrm{W} / 4+1.5+\mathrm{D}$ \\
\hline Back waist measurement & $\mathrm{W} / 4+1.5+\mathrm{D}$ & $\mathrm{W} / 4+2+\mathrm{D}$ \\
\hline Front hip measurement & $\mathrm{H} / 4+1+0.5$ & $\mathrm{H} / 4+2+0.5$ \\
\hline Back hip measurement & $\mathrm{H} / 4+1-0.5$ & $\mathrm{H} / 4+3-0.5$ \\
\hline Waist to hip length & 20 & 20 \\
\hline $\begin{array}{l}\text { Hollowed amount of back } \\
\text { center line (waist) }\end{array}$ & 1 & 0.5 \\
\hline $\begin{array}{l}\text { Hollowed amount of back } \\
\text { center line (hip) }\end{array}$ & 1 & 0.5 \\
\hline Hollowed amount of side line & 1 & 0.5 \\
\hline $\begin{array}{l}\text { Added amount to the front } \\
\text { length due to the front } \\
\text { hiking caused by big bust }\end{array}$ & 3 & 3.5 \\
\hline Bust point-bust point & $\mathrm{B} / 10+0.5$ & $\mathrm{~B} / 10+1.5$ \\
\hline Neck point to breast point & $\begin{array}{l}\text { Measured } \\
\text { value }\end{array}$ & $\begin{array}{l}\text { Measured } \\
\text { value }\end{array}$ \\
\hline
\end{tabular}

B(bust circumference), W(waist circumference), H(hip circumference), D(dart)
시한 것이다.

노년 비만여성의 착용만족도를 높이기 위해 그동 안의 연구는 비만부위 특히 신체 특정 부위(앞허리둘 레, 뒤엉덩이둘레)만의 치수를 크게 하는 방식으로 패턴을 수정하였는데, 이로 인해 제도된 패턴의 형태 가 기본 틀을 벗어나 좋지 못한 외관을 보여주는 결 과를 나타내었다. 따라서 본 연구는 기본적인 패턴의 형태를 유지하면서 특정 비만 부위에 여유량을 주기 보다, 앞뒤 여유량의 고른 배분을 통해서 패턴의 형 태를 유지하면서 신체적 특징을 커버할 수 있는 패턴 을 제작하고자 하였다.

젖가슴둘레는 전체적으로 여유가 많아 $\mathrm{B} / 2+4$ 로 $1 \mathrm{~cm}$ 줄여 설정하였다. 등길이와 엉덩이옆길이는 실측치를 사용하였고, 진동깊이는 젖가슴둘레선 처짐과 진동둘 레 파임 현상으로 비교원형보다 $1.5 \mathrm{~cm}$ 줄여 $\mathrm{B} / 4-1.5$ 로 설정하였다. 비만체형의 경우, 측면 두께가 두꺼운 신체적 특징을 갖고 있어, 겨드랑앞벽사이길이(앞품), 겨 드랑뒤벽사이길이(뒤품), 겨드랑너비의 균형이 맞지 않을 경우 진동둘레의 들뜸현상이 나타나는데, 비교원 형의 경,우 앞진동둘레 들뜸현상이 나타나 이를 위해 겨드랑앞벽사이길이(앞품)을 $0.7 \mathrm{~cm}$ 줄여 $\mathrm{B} / 6+2.3$ 으 로 설정하여 균형을 맞추고 진동둘레 들뜸현상을 수 정하였다. 목둘레의 들뜸현상도 젖가슴둘레를 기준으 로하는 계산식의 경우 비만체형은 일반체형보다 치수 가 큼으로 앞목너비와 앞목깊이를 $0.5 \mathrm{~cm}, 1 \mathrm{~cm}$ 를 줄여

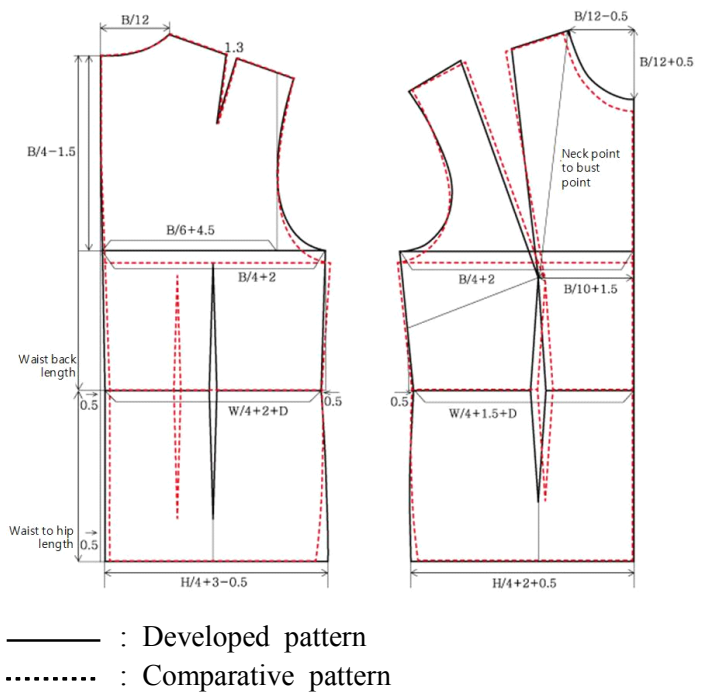

<Fig. 1> Developed torso pattern drafting method 
$\mathrm{B} / 12-0.5, \mathrm{~B} / 12+0.5$ 를 적용하였다. 허리둘레와 엉덩 이둘레의 경우, 앞허리와 배의 돌출로 측면의 당김현 상을 해결하기 위해 적당한 여유량의 배분이 필요한 데, 특히 돌출된 앞허리와 뒤엉덩이에 여유량을 주기 보다 앞허리둘레 $(\mathrm{W} / 4+1.5+\mathrm{D})$ 는 그대로 유지한 채 뒤 허리둘레 $(\mathrm{W} / 4+2+\mathrm{D})$ 에 $0.5 \mathrm{~cm}$, 앞엉덩이둘레 $(\mathrm{H} / 4+2+0.5)$ 에 $1 \mathrm{~cm}$, 뒤엉덩이둘레 $(\mathrm{H} / 4+3-0.5)$ 에 $2 \mathrm{~cm}$ 의 적당한 여유량 배분으로 당김현상을 완화하고, 패턴의 형태 도 균형을 유지하도록 했다. 또한 허리와 엉덩이둘레 의 여유량을 좀 더 주기 위해 뒤중심선에서 허리선과 엉덩이선으로 들어오는 분량과 옆허리선에서 들어오 는 옆선의 분량을 $0.5 \mathrm{~cm}$ 로 줄여주어 여유량을 좀 더 확보하고, 허리, 엉덩이둘레의 여유량이 골고루 배분 되도록 앞뒤다아트를 이동하여 패턴을 완성하였다.

\section{N. Conclusion}

본 연구는 증가하고 있는 노년 비만여성의 기성복 착용만족도를 향상시키기 위해 비만여성의 신체적 특 징을 보완한 토르소 원형을 개발하는 목적으로 연구 되었다. 연구과정에서 디지털 패션의 생산기술인 $3 \mathrm{D}$ 가상착의 프로그램을 활용하여 가상모델을 제작하고, YUKA 시스템을 이용하여 토르소 원형을 제작한 후, $3 \mathrm{D}$ 시뮬레이션을 통해 가상착의 및 보정을 하여 노 년 비만여성의 체형에 적합한 토르소 원형을 제시하 였다. 연구결과를 요약하면 다음과 같다.

첫째, CLO 3D 프로그램을 통해 구현하여 제시한 비만 인체모형은 3 가지 형태로 유형 1 은 상체에 비해 배가 발달한 하체비만 체형이고, 유형 2 는 허리가 비 만해서 가슴부터 배까지 일자형태를 이루는 비만형 으로 상체가 발달한 복부비만 체형이다. 유형 3은 전 체가 비만하지만 균형 잡힌 비만형으로 전신비만 체 형의 특징을 갖고 있다.

둘째, 비교원형의 가상착의 상태를 살펴본 결과, 목둘레선이 넓고 깊게 파여 좋지 못한 외관을 형성하 였고, 암홀의 상태는 가슴이 비교적 작은 유형 1 을 빼 고 나머지 두 체형 모두 넓고 깊게 파여 겨드랑 부위 가 들뜨고 젖가슴둘레선이 아래로 처지는 현상이 나 타났다. 허리둘레의 경우 모든 체형에서 뒤허리둘레 의 여유가 많아 좋지 못한 외관을 보여주고 있으며 배 부위와 엉덩이 부위의 당김현상은 유형 2 와 유형
3에서 두드러지게 나타났다. 또한 뒤다아트가 중심 쪽으로 몰려있는 것으로 나타나, 이를 바탕으로 목둘 레 여유량, 진동깊이와 젖가슴둘레선의 위치, 뒤허리 둘레와 앞뒤엉덩이둘레의 여유량에 대한 보정 및 여 유량 배분에 따른 앞뒤 다아트 위치의 적절성도 고려 하여 최종 연구원형을 설계하였다.

셋째, 비교원형의 가상착의 결과에 따라 나타난 문 제점을 수정한 최종 연구원형의 설계 결과는 다음과 같다. 젖가슴둘레를 가로 $(\mathrm{B} / 2+4)$ 로 $1 \mathrm{~cm}$ 줄여주고, 등 길이와 엉덩이옆길이는 실측치를 사용하였다. 진동깊 이는 젖가슴둘레선 처짐과 진동둘레 파임으로 비교원 형보다 $1.5 \mathrm{~cm}$ 줄여 $\mathrm{B} / 4-1.5$ 로 설정하였다. 앞진동둘 레 들뜸현상은 겨드랑앞벽사이길이(앞품)을 $0.7 \mathrm{~cm}$ 줄 여 $\mathrm{B} / 6+2.3$ 로 설정하여 겨드랑앞벽사이길이(앞품), 겨 드랑뒤벽사이길이(뒤품), 겨드랑너비의 균형을 맞추 고, 진동둘레 들뜸현상을 수정하였다. 목둘레의 들뜸 현상도 앞목너비와 앞목깊이를 각각 $0.5 \mathrm{~cm}, 1 \mathrm{~cm}$ 줄 여 $\mathrm{B} / 12-0.5, \mathrm{~B} / 12+0.5$ 로 적용하여 수정하였다. 배의 돌 출로 인한 측면의 당김현상은 특히 돌출된 앞허리와 뒤엉덩이에 여유량을 주기보다 앞허리둘레(W/4+1.5+ $\mathrm{D})$ 는 그대로 유지하고 뒤허리둘레 $(\mathrm{W} / 4+2+\mathrm{D})$ 에 $0.5 \mathrm{~cm}$, 앞엉덩이둘레 $(\mathrm{H} / 4+2+0.5)$ 에 $1 \mathrm{~cm}$, 뒤엉덩이둘레 $(\mathrm{H} / 4+$ 3-0.5)에 $2 \mathrm{~cm}$ 의 적당한 여유량 배분으로 당김현상을 완화하고, 패턴의 형태도 균형을 유지하도록 했다. 또 한 허리와 엉덩이둘레의 여유량을 좀더 주기 위해 뒤 중심선에서 허리선과 엉덩이선으로 들러오는 분량과 옆허리선에서 들어오는 옆선의 분량을 $0.5 \mathrm{~cm}$ 로 줄여 주어 여유량을 좀 더 확보하고, 허리둘레와 엉덩이둘 레의 여유량이 골고루 배분되도록 앞뒤다아트를 이 동하여 패턴을 완성하였다.

넷째, 연구원형의 가상 착의 결과는 앞목너비와 앞 목깊이의 축소로 목둘레의 들뜸현상이 개선되었고, 측 면에서 보면 진동깊이의 축소로 진동둘레의 들뜸이 나 파임이 개선되고, 젖가슴둘레의 처짐이 완화되었 다. 또 허리와 배 돌출로 인한 측면의 당김현상은 뒤 허리둘레와 앞뒤엉덩이둘레의 여유량 증가와 뒤허리 선과 옆허리선의 들임분량 축소로 인한 허리 여유량 증가로 개선되었고, 앞뒤다아트의 위치이동으로 인해 여유량이 적당이 배분되어 외관이 향상되었음을 알 수 있다. 외관평가 결과도 세 체형 모두에서 비교적 고르게 평가되어 비교원형에 비해 연구원형이 노년 
비만체형에 적합한 원형임을 알 수 있다.

본 연구는 기본 원형을 기반으로 특정 비만 부위에 만 여유량을 주기보다, 앞뒤 여유량의 고른 배분을 통해 토르소 원형의 형태를 유지하면서, 신체적 특징 을 커버할 수 있는 패턴을 제작하고자 하였다. 또한 외모에 대한 자심감이 부족한 비만체형의 피험자를 대상으로 $3 \mathrm{D}$ 프로그램을 활용한 가상모델 제작 및 패턴개발, 가상착의 등 일련의 제작과정은 의류업체 의 실용화에 기여할 것으로 여겨진다.

지금까지 비만체형의 형태적 특징을 고려하지 않 고, 단순히 인체측정치에 따라 제작한 의복의 경우, 맞음새에 불만족이 발생하였고, 이는 구매의욕 감소 로 이어져 비만여성을 위한 의류시장 확대에 지장을 초래하였다. 그러나 본 연구를 통해 비만여성의 체형 을 고려한 패턴을 개발함으로써 착용 만족도가 높아 지고, 구매의욕 상승으로 이어져 실버의류산업 활성 화에 기여하리라 생각된다.

그러나 실제 비만체형에 대한 착의검증이 이루어 지지 않아, 이 연구원형을 일반화하는데는 신중을 기 해야 한다. 따라서 후속연구는 실제 비만체형과 가상 모델에 대한 착의평가 비교연구와 토르소 원형의 사 이즈별 그레이딩에 대한 착의평가 연구가 체계적으 로 이루어져야 의류업체의 $3 \mathrm{D}$ 프로그램을 활용한 샘 플제작 및 피팅, 생산까지 실용화가 가능할 것으로 생각된다.

\section{References}

Choi, J., \& Do, W. H. (2008). Analysis on lower body type and 3D virtual appearance evaluation of boots cut jeans for women. Family and Environment Research, 46(2), 73-83.

Do, W. H., \& Park, H. J. (2010). A study on the fit preferences of knitted jackets according to body types using a 3D virtual try-on system: Focus on adult women in their 30's and 40's. Journal of the Korean Society of Clothing and Textiles, 34(10), 1632-1646. doi:10.5850/JKSCT.2010.34. 10.1632

Hong, E. H. (2013). Development of tight-fit torso patterns according to adult men's somatotype using surface flattening of $3 D$ body scan data: Using a $3 D$ virtual garment system. Unpublished doctoral dissertation, Hanyang University, Seoul, Korea.

Hong, E.-H., Kim, K.-A., \& Uh, M.-K. (2015). Comparative analysis of pants pattern and virtual appearance evaluation for men's single-pleated pants. Journal of the Korea Fashion \& Costume Design Association, 17(1), 105-115.

Kim, H.-S. (2007). A study on body shapes using 3D measurement and torso pattern of obese women. Unpublished doctoral dissertation, Sungshin Women's University, Seoul, Korea.

Kim, K.-A., Hong, E.-H., \& Uh, M.-K. (2014). Comparative analysis of men's slim pants patterns: Using a 3D CLO virtual garment system. The Research Journal of the Costume Culture, 22(4), 605-618. doi:10.7741/rjcc.2014.22.4.605

Kim, M. J., Kim, M.-O., \& Park, S. K. (2014). Comparison and analysis of men's classic-fit and slim-fit shirt patterns: Utilizing the $3 \mathrm{D}$ virtual tryon system. The Research Journal of the Costume Culture, 22(2), 209-224. doi:10.7741/rjcc.2014.22. 2.209

Kim, S. J., Choi, J., Jo, H. E., Yang, E. G., \& Na, Y. H. (2015). Digital fashion design. Paju: Gyomoonsa.

Kim, Y. S., Yin, S. Y., \& Song, H. K. (2014). A comparison of fit and appearance between real torso length sloper with $3 \mathrm{D}$ virtual torso length sloper. The Research Journal of the Costume Culture, 22(6), 911-929. doi:10.7741/rjcc.2014.22.6. 911

Korean Agency for Technology and Standards. (2004). 제5차 한국인 인체치수 조사사업보고서 [The fifth human body Measurement report (Size Korea)]. Gwacheon: Ministry of Knowledge Economy.

Lee, M. J., \& Sohn, H. S. (2011). A study on the cases of the application of $3 \mathrm{D}$ apparel CAD system to the domestic and overseas fashion education. Jour- 
nal of the Korean Society of Clothing and Textiles, 35(9), 1112-1124. doi:10.5850/JKSCT.2011. 35.9.1112

Lee, M. J., \& Sohn, H. S. (2012). A comparative analysis of the different between CLO 3D Avatar sizing and actual body measurement shapes. Journal of Fashion Business, 16(4), 137-151. doi:10. 12940/jfb.2012.16.4.137

Lee, H. S., Yoon, M. K., Park, J. K., \& Nam, Y. J. (2013). 블라우스-원피스 드레스: 어패럴 메이킹 [Blouse-dress: Apparel making]. Seoul: Kyohakyungusa.

Lee, J.-J., \& Suh, M.-A. (2010). Slacks purchase realities and wearing satisfaction: Focused on oldaged women. The Research Journal of the Costume Culture, 18(3), 541-549.

Li, E. Y. (2013). Development of tight-fitting shape one piece prototype pattern: Centered on women in their twenties wearing a C cup. Unpublished master's thesis, Gachon University, Gyeonggi-do, Korea.

Lim, J. Y. (2010). A development of the torso pattern for obese middle-aged women from 3D virtual garment simulation. Fashion \& Textile Research Journal, 12(1), 86-93. doi:10.5805/KSCI.2010.12. 1.086

Lim, J. Y. (2013). Development of torso pattern for underweight female in their 20s 30s: Using Clo 3D program. Fashion \& Textile Research Journal, 15(6), 963-970. doi:10.5805/SFTI.2013.15.6. 963

Ryu, H. S. (2001). 여성복 패턴메이킹 [Pattern making]. Seoul: Suhaksa.

Seong, O. J., \& Kim, S. J. (2015). Study on the body shapes of old aged obese women for the activation of the silver clothing industry. The Research Journal of the Costume Culture, 23(5), 755-767. doi:10.7741/rjec.2015.23.5.755

Yoon, J. W. (2013). The development of tight fit torso patterns with body type of women by $3 D$ body scan data: Using the virtual appearance evaluation. Unpublished doctoral dissertation, Hanyang University, Seoul, Korea. 